
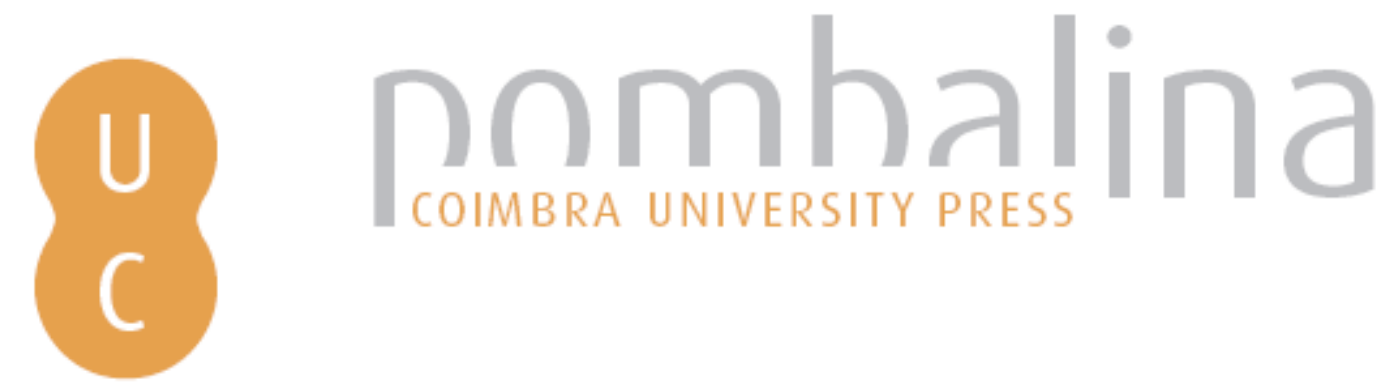

\title{
Projectos de educação para o desenvolvimento e a cidadania no contexto académico: estudo de caso do curso de geografia da Universidade do Minho
}
Autor(es):
Costa, Francisco da Silva; Remoaldo, Paula Cristina
Publicado por: Imprensa da Universidade de Coimbra
URL
persistente:
URI:http://hdl.handle.net/10316.2/30756
DOI:
DOI:http://dx.doi.org/10.14195/978-989-26-0244-8_5
Accessed : $\quad$ 26-Apr-2023 12:35:26

A navegação consulta e descarregamento dos títulos inseridos nas Bibliotecas Digitais UC Digitalis, UC Pombalina e UC Impactum, pressupõem a aceitação plena e sem reservas dos Termos e Condições de Uso destas Bibliotecas Digitais, disponíveis em https://digitalis.uc.pt/pt-pt/termos.

Conforme exposto nos referidos Termos e Condições de Uso, o descarregamento de títulos de acesso restrito requer uma licença válida de autorização devendo o utilizador aceder ao(s) documento(s) a partir de um endereço de IP da instituição detentora da supramencionada licença.

Ao utilizador é apenas permitido o descarregamento para uso pessoal, pelo que o emprego do(s) título(s) descarregado(s) para outro fim, designadamente comercial, carece de autorização do respetivo autor ou editor da obra.

Na medida em que todas as obras da UC Digitalis se encontram protegidas pelo Código do Direito de Autor e Direitos Conexos e demais legislação aplicável, toda a cópia, parcial ou total, deste documento, nos casos em que é legalmente admitida, deverá conter ou fazer-se acompanhar por este aviso.

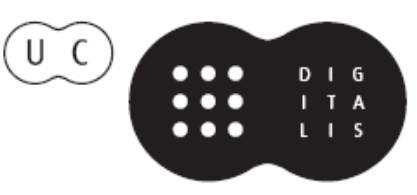




\section{TRUNFOS DE UMA}

\section{EOGRAFIA ACIVA}

\section{DESENVOLVIMENTO LOCAL,}

AMBIENTE,

ORDENAMENTO

E TECNOLOGIA

Norberto Santos

Lúcio Cunha

COORDENAÇÃO 
Francisco da Silva Costa, Paula Cristina Remoaldo

NIGP, Departamento de Geografia, Universidade do Minho

\author{
PROJECTOS DE EDUCAÇÃO PARA O DESENVOLVIMENTO E \\ A CIDADANIA NO CONTEXTO ACADÉMICO \\ - ESTUDO DE CASO DO CURSO DE GEOGRAFIA DA UNIVERSIDADE DO MINHO
}

O MEU CONTRIBUTO PARA TORNAR O MUNDO MAIS SUSTENTÁVEL
- DESAFIO NO ÂMBITO DA UNIDADE CURRICULAR DE “GEOGRAFIA HUMANA”

\title{
ENQUADRAMENTO E OBJECTIVOS DA UNIDADE CURRICULAR
}

Foi em Maio de 1998 que se iniciou a discussão da criação de um Espaço Europeu do Ensino Superior através da Declaraçáo de Sorbonne, que foi subscrita por quatro países (França, Alemanha, Itália e Reino Unido). No ano seguinte, a 19 de Junho de 1999, passou para 29 países o número de subscritores da designada Declaração de Bolonha. No sentido de se alcançarem os objectivos de harmonizaçáo e uniformização do Espaço Europeu do Ensino Superior, a Declaração de Bolonha foi ancorada na competitividade do Sistema Europeu de Ensino Superior e na mobilidade e empregabilidade no Espaço Europeu.

Com a entrada em vigor do paradigma de Bolonha, foram aprovados pela tutela, em 2006, alguns dos Cursos de $1^{\circ}$ Ciclo e de $2^{\circ}$ Ciclo de Geografia das Universidades portuguesas e o da Universidade do Minho foi um dos que optou por iniciar a aplicaçáo do novo plano curricular do $1^{\circ}$ Ciclo no ano lectivo de 2006/2007 (Resoluçáo no 85/2006 publicado no Diário da República, 2a Série, no 156, de 14 Agosto).

Com base nestes factos passámos a ter como metas nas aulas práticas da unidade curricular de Geografia Humana ( $1^{\circ}$ ano do Curso), o desenvolvimento integral da pessoa, estando, deste modo, subjacente uma visão holística, bem como, o desenvolvimento de um espírito crítico em relação à intervenção do ser humano na superfície da terra. Este último aspecto constitui, aliás, um dos deveres dos docentes, de acordo com o Estatuto da Carreira Docente Universitária (E.C.D.U.) em vigor no ano lectivo de 2008/2009, no seu artigo $63^{\circ}$ (Deveres do docente).

Neste sentido, optámos por propor um desafio aos alunos, nas aulas práticas da mencionada unidade curricular. Os objectivos principais do trabalho individual que foi proposto, intitulado "O meu contributo para tornar o mundo mais sustentável" foram:

- Definir alguns conceitos (e.g., Ambiente, Desenvolvimento Sustentável, Empowerment);

- Avaliar a situação portuguesa no que diz respeito ao ambiente;

- Mudar, a curto prazo, comportamentos do quotidiano; 
- Contribuir, a curto prazo, para um mundo mais sustentável;

- Reflectir sobre o papel futuro como Geógrafo(a).

Pretendemos também envolver os estudantes no Projecto "Oito Maneiras de Mudar o Mundo", financiado pelo Ministério dos Negócios Estrangeiros e desenvolvido pela U.C.C.L.A. (União das Cidades Capitais Luso-Afro-Américo-Asiáticas) e URB-ÁFRICA (Associação para a Cooperação e Desenvolvimento Urbano) com a parceria do Núcleo de Investigação em Geografia e Planeamento (N.I.G.P.) da Universidade do Minho. O principal objectivo deste Projecto, desenvolvido entre Março de 2008 e Julho de 2009 foi fomentar uma mudança de valores e comportamentos no âmbito da cidadania, solidariedade e participação social no espaço público português.

Em termos de estrutura do trabalho a desenvolver os estudantes foram confrontados com a tentativa de definição de alguns conceitos, tais como: Ambiente, Desenvolvimento Sustentável, Globalização, Protocolo de Quioto, Oito Objectivos do Milénio e Empoderamento. Seguidamente, tentaram aferir a situação portuguesa em várias vertentes do Ambiente, sobretudo na componente física. A intervenção por parte de várias instituiçôes (e.g., Banco Espírito Santo, Caixa Geral de Depósitos, Sociedade Ponto Verde, BRAVAL, Pingo Doce), no sentido de se atingir o Objectivo Sétimo do Milénio (Garantir a Sustentabilidade Ambiental) foi também focalizada nas aulas práticas.

Além disso, os estudantes realizaram uma análise introspectiva dos seus comportamentos encetados no quotidiano, avançando com o que fazem de positivo (pelo menos cinco comportamentos) e o que fazem de negativo (pelo menos cinco comportamentos). Esta análise conduziu a uma proposta de mudança de comportamentos (cinco comportamentos) a curto prazo.

Por último, foram organizadas duas palestras (Outubro de 2008 e Janeiro de 2009), que se debruçaram sobre a vermicompostagem (Objectivo 7 do Milénio) e sobre a desconstruçáo de estereótipos de género (Objectivo 3 do Milénio).

\section{ALGUNS RESULTADOS}

A primeira ilação a retirar prende-se com o facto de a maior parte dos alunos não deter uma visão integrada e sistémica de alguns conceitos, tais como, o de "Ambiente", tendendo a centrar-se apenas na componente física e biológica, descurando a componente cultural. Mesmo no seio da vertente física foi diagnosticada uma certa dificuldade em concretizar o que abarca (circundantes físicos e químicos do ar, terra e mar; constantes físicas - gravidade - variáveis geográficas como os solos, o clima, a altitude e a continenta-lidade). Os conceitos de "Desenvolvimento Sustentável" e "Globalizaçáo" foram os mais bem definidos, enquanto o de "Protocolo de Quioto" e os "Oito Objectivos do Milénio (O.D.M.)” eram conhecidos apenas por parte de alguns estudantes. Pelo contrário, o conceito Empowerment foi introduzido pela docente e definido como the process of increasing the capacity of individuals or groups to make choices and to transform those choices into desired actions and outcomes (www. worldbank.org - acedido a 25/02/2009). No que respeita aos comportamentos dos estudantes, ressaltam dois níveis de comportamentos. O primeiro nível diz respeito a comportamentos mais básicos, mais simplistas e o segundo nível centra-se em comportamentos mais complexos, pressupondo a assimilação dos comportamentos mais básicos. 
Os comportamentos mais frequentemente invocados, pelos trinta e três estudantes que realizaram o relatório, como sendo prática no seu quotidiano podem ser divididos em dois níveis apresentando alguns exemplos:

- Comportamentos de nível 1 - Poupar água, poupar electricidade (chuveiro e ferro), redução do consumo e da produção de resíduos, participação na separação selectiva de resíduos sólidos urbanos;

- Comportamentos de nível 2 - Votar de forma consciente; conhecer a legislação ambiental e manter-se informado sobre as questóes ambientais, participar numa O.N.G.D., reutilizaçáo de materiais (e.g., boióes), reeducaçáo dos familiares e amigos, reeducaçáo no sentido de diminuir o consumismo em geral (estilo de vida), respeito pela natureza, reutilização da água.

Estes comportamentos revelam que estamos perante uma geração que teve alguma formação no ensino não superior em termos ambientais resultante da inclusão no seu plano curricular da "Área de Projecto" e da "Formação Cívica". Os resultados também deixam transparecer que os comportamentos encetados estão consonantes com as campanhas difundidas nas últimas décadas pelos mass media (e.g., separação de resíduos sólidos, economia de energia eléctrica). Também não podemos descurar o facto de ser uma geração que assistiu ao despertar da opinião pública resultante da passagem do Filme de Al Gore Verdade Inconveniente e da mensagem passada no ano de 2006 e 2007 tendo como alicerce o impacto da acção antrópica no planeta Terra (Quadro 1).

Quadro 1 - Principais comportamentos positivos dos estudantes

\begin{tabular}{|l|l|}
\hline \multicolumn{1}{|c|}{ Comportamentos positivos } & No \\
\hline Poupa energia & 32 \\
\hline Poupa água e usa-a de forma racional & 24 \\
\hline Faz separaçáo selectiva de resíduos sólidos & 21 \\
\hline $\begin{array}{l}\text { Evita uso de automóvel e/ou utiliza transportes públicos e/ou outras formas de } \\
\text { transporte }\end{array}$ & 15 \\
\hline Reutiliza água & 9 \\
\hline Não atira objectos para o chão (e.g., papéis de rebuçado, pastilhas elásticas) & 8 \\
\hline $\begin{array}{l}\text { Evita produçáo de resíduos (evita compra de produtos enlatados; evita uso de } \\
\text { sacos de plástico) }\end{array}$ & 7 \\
\hline Reutiliza determinados produtos (e.g., caixas de cartáo) & 6 \\
\hline Sensibiliza terceiros - amigos e familiares & 6 \\
\hline $\begin{array}{l}\text { Contribui para instituiçóes (doa bens) e/ou colabora em campanhas de } \\
\text { solidariedade }\end{array}$ & 4 \\
\hline Não fuma - não polui nem prejudica quem o/a rodeia & 4 \\
\hline Preserva os espaços verdes (náo pisa relva em áreas ajardinadas) & 139 \\
\hline Total & 3 \\
\hline
\end{tabular}

Fonte: Relatório realizado pelos estudantes do $1^{\circ}$ ano do Curso de Geografia e Planeamento.

A poupança de energia $(n=32)$ e de água $(n=24)$ foram os comportamentos mais referenciados, porque lhes está subjacente a necessidade de uma poupança nos gastos famíliares e num período de crise económica ainda mais significado deverá ter. Enquanto a poupança de electricidade diminui a construção de hidroeléctricas que causam danos ambientais (e.g., represam rios, reduzem o stock de peixes, aniquilam animais, alteram o 
regime dos rios) a água potável é um recurso natural escasso, em muitas partes do mundo. Hoje, cerca de 36 países estão em guerra por causa da água e outros 60 estão em conflito e nalguns países 1 litro de água custa mais do que 1 litro de gasolina (Dias, 2005).

As inúmeras campanhas levadas a cabo nos últimos anos e difundidas na televisão relacionadas com a separação selectiva de resíduos sólidos urbanos e o investimento de muitas autarquias para proporcionar uma grande proximidade do munícipe aos ecopontos devem ter contribuído determinantemente para a significativa fatia de alunos que realizam separação selectiva de resíduos urbanos. A participação na separação selectiva de resíduos sólidos urbanos significa menos consumo de água, energia eléctrica e matéria-prima e desflorestação de uma forma geral (Dias, 2005: 9).

Parece-nos ser relevante o número de estudantes que se preocupa em sensibilizar amigos e familiares $(n=6)$, apresentando três elementos idades entre 30 e 35 anos.

Outros comportamentos prendem-se com a preservação dos espaços verdes (não pisa relva em áreas ajardinadas $-\mathrm{n}=3)$, com a poupança de papel $(\mathrm{n}=2)$, com a realizaçáo de compostagem $(n=2)$ e com a utilizaçáo de cinza da lareira como fertilizante $(n=1)$.

As respostas são similares às dos estudantes do ano lectivo de 2006/07, mas a maior diferença tem a ver com o facto dos estudantes de 2008/2009 estarem mais centrados na separação de resíduos.

Quando questionados sobre os comportamentos negativos empreendidos no quotidiano fomos confrontados com a consciência de que a não separação de resíduos sólidos era o comportamento menos positivo (Quadro 2). Os comportamentos apresentados são fáceis de modificar, tendo sido mencionados como alguns dos comportamentos que pretendiam modificar a curto prazo.

Quadro 2 - Principais comportamentos negativos dos estudantes

\begin{tabular}{|l|c|}
\hline \multicolumn{1}{|c|}{ Comportamentos positivos } & No \\
\hline Não faz separação de resíduos sólidos & 9 \\
\hline Utiliza de forma excessiva o automóvel & 7 \\
\hline Não poupa papel & 6 \\
\hline Não utiliza produtos descartáveis & 6 \\
\hline Não preserva os espaços verdes (pisa ou danifica relva e áreas ajardinadas & 4 \\
\hline Não utiliza pilhas recarregáveis & 3 \\
\hline Atira papéis, papéis de rebuçados e pastilhas elásticas para o chão & 3 \\
\hline Total & 38 \\
\hline
\end{tabular}

Fonte: Relatório realizado pelos estudantes do $1^{\circ}$ ano do Curso de Geografia e Planeamento.

COMO DESENVOLVER UM PROJECTO DE DESENVOLVIMENTO PARA A SUSTENTABILIDADE LOCAL - UM EXEMPLO A PARTIR DA UNIDADE CURRICULAR DE “CIDADANIA E AMBIENTE”

O segundo exemplo desenvolvido no seio do Projecto mencionado no item 1 reportase à unidade curricular de Cidadania e Ambiente, que faz parte do segundo ano do plano de estudos do $1^{\circ}$ Ciclo de Geografia e Planeamento. Entre os seus objectivos destacam-se a consciencialização dos alunos para o papel da educaçáo para o desenvolvimento sustentável e o reforço da Geografia, na sua vertente transdisciplinar, nos projectos de educação ambiental. 
No âmbito do projecto "Oito Maneiras de Mudar o Mundo" realizaram-se quatro palestras que decorreram nas aulas práticas do mês de Março de 2009, com a participação de alguns especialistas de várias áreas, proporcionando um debate sobre os Oito Objectivos do Milénio. Nestas palestras foram desenvolvidas diferentes práticas pedagógicas e criadas situaçóes e experiências de aprendizagem que permitiram uma familiarização com os temas dos O.D.M..

Nas restantes aulas práticas, foi sugerida a elaboração de um projecto de educação ambiental, numa sequência metodológica adequada aos conteúdos programáticos da unidade curricular e enquadrada no âmbito do Sétimo Objectivo do Milénio (Garantir a sustentabilidade ambiental). Assim, foi lançado um desafio para os grupos constituídos, que, num primeiro momento, identificaram os diferentes problemas de sustentabilidade à escala global (os 5 mais importantes) e local (os 3 mais significativos - Quadro 3).

Quadro 3 - Síntese dos principais problemas de sustentabilidade ambiental apresentados pelos alunos da unidade curricular de "Cidadania e Ambiente"

\begin{tabular}{|l|l|l|}
\hline \multirow{2}{*}{\multicolumn{1}{|c|}{ Grupos }} & \multicolumn{2}{c|}{ Problemas de sustentabilidade ambiental } \\
\cline { 2 - 3 } & \multicolumn{1}{|c|}{ Global } & \multicolumn{1}{c|}{ Local } \\
\hline G1 & Aquecimento global & Poluição aquática \\
\hline G2 & Consumismo & Poluição aquática \\
\hline G3 & Poluiçáo & Desordenamento \\
\hline G4 & Desigualdades & Poluiçáo atmosférica/sonora \\
\hline G5 & Esgotamento energético & Desemprego \\
\hline \multicolumn{2}{|c|}{ Fonte: Trabalho prático realizado pelos estudantes do $2^{\circ}$ ano do Curso de Geografia e Planeamento. }
\end{tabular}

Os resultados demonstram diferenças significativas entre os grupos, principalmente se a análise é feita à escala global. Nota-se também alguma dificuldade em situar correctamente, do ponto de vista científico, a designação de sustentabilidade e a inter-relação entre as suas diferentes dimensóes, nomeadamente a ambiental.

Após este exercício e o respectivo debate, os grupos seleccionaram o problema de sustentabilidade local sobre o qual assentaria a proposta a desenvolver de projecto de educação ambiental. Para uma melhor planificação do relatório a entregar, foram sugeridos um conjunto de itens a considerar no planeamento do projecto de educaçáo ambiental (Quadro 4).

Quadro 4 - Proposta de planeamento de um projecto de educação ambiental

\begin{tabular}{|l|l|}
\hline \multicolumn{1}{|c|}{ Item } & \multicolumn{1}{c|}{ Principais aspectos a ter em conta } \\
\hline \multirow{4}{*}{ Tema } & - Selecção do tema \\
& - Contextualização \\
& - Problematização \\
& - Pressupostos \\
& - Expectativas/potencialidades \\
\hline \multirow{5}{*}{ Fundamentação teórica } & - Definição de objectivos \\
& - Justificação \\
& - Relevância \\
& - Descrição do projecto \\
& - Populaçáo-alvo \\
\hline
\end{tabular}




\begin{tabular}{|l|l|}
\hline Metodologia & - Estratégia \\
& - Métodos \\
\hline \multirow{3}{*}{ Recursos } & - Humanos \\
& - Equipamento/logística \\
& - Financeiros \\
& - Material pedagógico \\
\hline \multirow{3}{*}{ Planeamento das actividades } & - Faseamento \\
& - Calendarizaçáo \\
\hline \multirow{2}{*}{ Realização das actividades } & - Coerência com os objectivos \\
\hline & - Registo de resultados \\
& - Tratamento de resultados \\
\hline \multirow{3}{*}{ Avaliaçáo } & - Expectativas vs. Resultados reais \\
& - Obstáculos vs. Facilidades \\
& - Conhecimentos adquiridos \\
& - Mudança de atitudes \\
\hline
\end{tabular}

Fonte: Sebenta da unidade curricular de Cidadania e Ambiente.

A proposta apresentada visava cobrir dois objectivos: responder ao estabelecido pela maior parte dos formulários de candidatura relativos aos concursos lançados por entidades públicas e ser possível a sua operacionalização no terreno, a curto prazo, no caso de vir a ser aceite.

Dos diferentes projectos apresentados, foram seleccionados os dois de maior qualidade para se constituírem como candidatura à terceira edição do Concurso AGIR Ambiente (Acçôes Gulbenkian de Informação e Realização em Ambiente), dedicada ao tema do consumo sustentável:

- "Butes Carona" - Este projecto pretende dar a conhecer o Carpooling, um movimento muito em voga recentemente em Portugal, mas já com bastante expressão a nível europeu. Através de um conjunto de acçóes, tem como objectivo a promoção de hábitos de deslocação mais sustentáveis, nomeadamente, a partilha do automóvel particular (ou a utilização dos transportes colectivos), por parte dos estudantes, docentes e funcionários do campus de Azurém, da Universidade do Minho;

- "À Volta da Horta" - Trata-se de um projecto que se preocupa com protecção dos solos férteis e com aptidão agrícola, principalmente aqueles que se localizam em ambiente urbano ou nas imediaçóes deste, pelo seu importante contributo na qualidade ambiental das cidades. A criação de um clube junto da comunidade académica visa promover o interesse e participação de alunos universitários na preservação das hortas comunitárias pertencentes à autarquia de Guimarães e na sensibilização da restante comunidade local.

A possibilidade de apresentar propostas concretas relacionadas com os principais problemas de sustentabilidade local torna-se sem dúvida, o principal desafio deste tipo de trabalhos, já que incentiva os alunos a participar, com o seu contributo, na resolução dos mesmos.

\section{CONSIDERAÇÓES FINAIS}

A inserção de práticas para o desenvolvimento e a cidadania no quadro académico possibilita aos alunos a aquisição de determinados objectivos: 
a) objectivos cognitivos - um conhecimento objectivo dos fenómenos e dos sistemas é um suporte essencial a uma boa apreensão dos problemas de sustentabilidade e desenvolvimentos e permite uma implicação eficaz na sua resolução: a vida - os ciclos - a biodiversidade - a adaptação - o equilíbrio dinâmico - a evolução - as inter-relaçóes entre seres vivos - a acção dos homens - a interpretação artística - a análise sistémica - o direito do ambiente - a história dos conflitos ambientais;

b) objectivos metodológicos - trata-se de adquirir métodos de trabalho diversificados, com vista a desenvolver a capacidade de observar, de compreender e de agir, com criatividade, lucidez e espírito de responsabilidade: - métodos científico, analítico e experimental, métodos artístico, lúdico, cultural, métodos global, interdisciplinar e sistémico;

c) objectivos comportamentais - a aquisição de novas atitudes face à natureza e ao ambiente torna-se urgente, desde o gesto mais simples à tomada de consciência responsável dos equilíbrios a preservar: favorecer um despertar sensível e emocional, uma capacidade de observação e de descoberta, uma prática de experimentação do terreno e da acção, atitude de pesquisa, autonomia e sentido de responsabilidade, desejo de aprender, sentido crítico, entre outros.

Tendo em conta o trabalho desenvolvido com os estudantes de Geografia, no âmbito das unidades curriculares "Geografia Humana" e "Cidadania e Ambiente", chegamos a algumas conclusóes que devem ser objecto de reflexão:

- Os grupos mostraram-se sensibilizados e preocupados com o exercício da cidadania, mas com dificuldades em organizarem-se colectivamente e mobilizarem-se em torno de causas comuns;

- É evidente a necessidade de descodificação de vários conceitos;

- Os alunos demonstram um conhecimento da situação portuguesa mais identificado com os problemas de sustentabilidade ambiental à escala local.

Mesmo assim, pode-se afirmar que a experiência foi positiva e encorajadora e veio reforçar o exercício de cidadania de todos os envolvidos.

\section{REFERÊNCIAS BIBLIOGRÁFICAS}

Costa, F.; Remoaldo, P.C. (2009), Principais desafios que se colocam a Portugal e intervençôes prioritárias no âmbito dos Oito Objectivos do Milénio, in Actas do Primeiro Congresso de Desenvolvimento Regional de Cabo Verde, XV Congresso da Associaçáo Portuguesa de Desenvolvimento Regional, Segundo Congresso Lusófono de Ciência Regional, Terceiro Congresso de Gestão e Conservação da Natureza, Cidade da Praia (Ilha de Santiago), Cabo Verde, 17 p. (no prelo).

Dias, G.F. (2005), 40 contribuiçôes pessoais para a sustentabilidade, São Paulo, Editora Gaia.

Moreira, A., Princesa, P.; Costa, F.; Remoaldo, P.C.; Gonçalves, A.B.; Vieira, A. (2009), Oito Maneiras de Mudar o Mundo - um Projecto de Educação para o Desenvolvimento, in Actas do X Congresso Luso-Afro-Brasileiro de Ciências Sociais, Universidade do Minho e Associação Portuguesa de Sociologia, 12 p. (no prelo).

Peixoto, P.; Moreira, A. (2007), Imaterial, Possivel, Inevitável - a viagem de um Projecto, Uniāo das Cidades Capitais Luso-Afro-Américo-Asiáticas (U.C.C.L.A.) e URB - África, Impressão pela Câmara Municipal de Lisboa. 


\section{FONTES ELECTRÓNICAS}

www.apambiente.pt (Agência Portuguesa do Ambiente)

www.dgs.pt (Direç̧ão-Geral da Saúde, Ministério da Saúde).

www.eea.eu.int (Agência Europeia do Ambiente)

64

www.eurohiv.org (European Centre for the Epidemiological Monitoring of AIDS)

www.ine.pt (Instituto Nacional de Estatística)

www.oikos.pt (Oikos - Cooperação e Desenvolvimento)

www.unep.org (Programa das Naçóes Unidas para o Ambiente)

www.unicef.pt (U.N.I.C.E.F.)

www.who.org (Organização Mundial de Saúde).

www.worldbank.org (World Bank) 